\title{
How advances in semiconductor technologies have adversely affected electrical and electronics installations in Africa
}

\author{
Sebastian K. Namukolo ${ }^{1}$, Evaristo Musonda ${ }^{2}$ \\ ${ }^{1}$ Department of Electrical and Electronic Engineering, University of Zambia, Box 32379, \\ Lusaka; Zambia \\ namukolo1@yahoo.com \\ ${ }^{2}$ Department of Electrical and Electronic Engineering, University of Zambia, Box 32379, \\ evaristo.musonda@unza.zm \\ Lusaka; Zambia
}

\begin{abstract}
This paper presents findings obtained in the Zambian national instrumentation surveys and highlights the little understood adverse effects that advances in semiconductor technology have on electrical and electronic instrumentation applied in all sectors in most African countries in particular Zambia. These effects have been occasioned by the lack of compliance to revised international installation and protection standards, poor power quality and poor planning compounded in many cases by severe weather conditions. These adverse impacts have been mainly caused by very high transistor integration in semiconductor (ICs). This has meant that electrical environment of yester year now requires vast improvements for the newer low dielectric strength component based equipment to operate reliably and safely. This paper finally describes good installation practices in power conditioning, earthing, bonding, surge and lightning protection solutions.
\end{abstract}

Keywords: semiconductor technology, low dielectric strength, electronic instrumentation, standards, integration, protection.

\section{Introduction}

Society's dependency on modern technology has been increasing at such a rate that it has affected all aspects of our everyday lives. All areas of our economic endeavors and wellbeing are in one way or other influenced by technology. However, the effectiveness of operation is heavily dependent on efficient technology utilization, especially when applied in the industrial and commercial area; this means fault-free and reliable operation of equipment. Equipment failure and installation destruction has been rising in Zambia and Africa generally over the past thirty years due to high integration of electronic circuitry (ICs) caused by reduced transistor dielectric strength [1]. Advances in material semiconductor technology has been able to integrate over a billion transistors in a single IC package, interconnected by thousands of wires which can fit in the width of a human hair [2]. Memory capacities and processing speeds have equally increased while power requirements for these devices have drastically reduced. However, these tiny closely packed components have very

ACRID 2017, June 20-21, Victoria Falls, Zimbabwe

Copyright (C) 2017

DOI 10.4108/eai.20-6-2017.2270803 
low dielectric strength, making them very tender and vulnerable to overvoltage damage as compared to the electromechanical components of the pre highly integrated circuit period. Now, very complex, but affordable ICT data processing installations are realizable which did not require costly cooling systems. In the African countries context, it is not uncommon to find this complex equipment being powered from unconditioned utility supply without the necessary power conditioning and protection measures. In addition, such installations are usually housed in poor electrical environments, a factor that has led to rise in equipment failure and malfunction.

From the early seventies, the National Council for Scientific Research (NCSR), predecessor of the present National Institute for Scientific and Industrial Research (NISIR) has been the focal point for activities in the field of nuclear sciences and technology in collaboration with the International Atomic Energy Agency (IAEA) in Zambia. These collaborative activities included nuclear instrumentation as applied in agriculture, medicine, industry and general research. [3], [4]. The principal author of this paper was the national coordinator of the national instrumentation program. Under these program activates, African member countries frequently met on equipment protection training workshops that addressed issues to do with equipment protection and instrumentation failure. In particular, a regular training program entitled "Power Conditioning, Earthing and Lightning Protection" was organized yearly, both in and outside Africa, where knowledge of instrumentation failure and solutions were shared. The IAEA technical cooperation regarding instrumentation program with African countries now has thirty-nine member states [4].

In most developing African countries, equipment manufacturer representation is non-existent. This situation leads to big problems such as prolonged costly downtime, repair costs and loss of life in critical intuitions like hospitals when equipment and systems require specialized manufacturers attention.

In Zambia, efforts to address the problem continues and in the past four years, the Zambian government instituted equipment installation and protection standardization programs under two regulatory bodies: The Zambia Information and Communications Authority (ZICTA) and the Zambia Bureau of Standards (ZABS). These bodies were tasked to institute technical committees'(TCs) to formulate national installation standards and guidelines aimed at reducing installation and equipment damage, as well as insuring human safety, for future enforcement and strict compliance.

\section{Zambia's prevailing equipment and electrical installation culture and improvements.}

From 1980 to 2002 the national instrumentation program between IAEA and Zambia conducted surveys in some institutions which revealed the following common problems: poor installations characterized by poor earthing and bonding, and lack of surge and lightning protection and in some cases lack of power conditioning. These problems were understood in view of the high semiconductor component integration. Appropriate remedial recommendations were made and implemented, with reported 
improvement from several of these institutions. Following is a list of some of the organizations where electrical and equipment installation studies were made: National Airports Corporation (NAC), Konkola Copper Mines (KCM), Zambia Revenue Authority (ZRA), Zambia Air Force (ZAF), Bank of Zambia (BOZ), Road Development Agency (RDA), University Teaching Hospital (UTH), and MTN.

\section{Instrument and system failure causes as found in the national surveys}

The following section summaries the causes of instrument and system failure as revealed in the national instrumentation surreys: [5], [6]

\section{a) Power line disturbances}

During the national surveys investigations revealed that power transients, sags, swells, low voltages and dropout were common (at Breeze FM radio station, Chipata, Eastern province, KCMs Chililabombwe, Nkana, Nchanga and Nampudwe mines; ZRAs Mansa, Siavonga, Katimamulilo, Kasama, Nakonde, Kazungula) and other corporates listed above. The figure below shows the type of powerline disturbances as encountered in the national surveys.

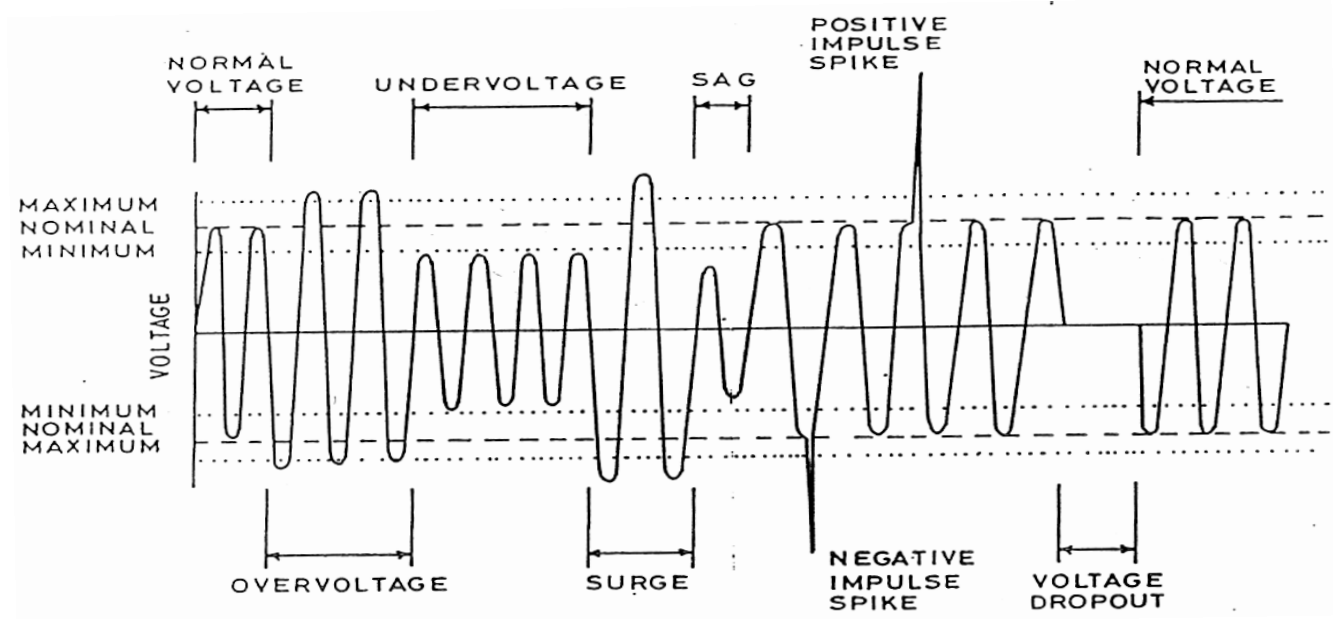

Fig. 1. Different types of power line disturbances on utility phase line. 


\section{b) Lightning strikes}

Zambia is a tropical sub-Saharan country, lying between $12^{\circ}$ and $29^{\circ}$ South: and $13^{\circ}$ and $27^{\circ}$ East. Lightning density increases northwards as one approaches the equatorial region. The national instrumentation surveys showed that sensitive electronic equipment incurred high rate of damages as one approached the northern region, especially that these instruments were not installed with the best practices regarding lightning protection. [6] below is an example of lightning caused damage.

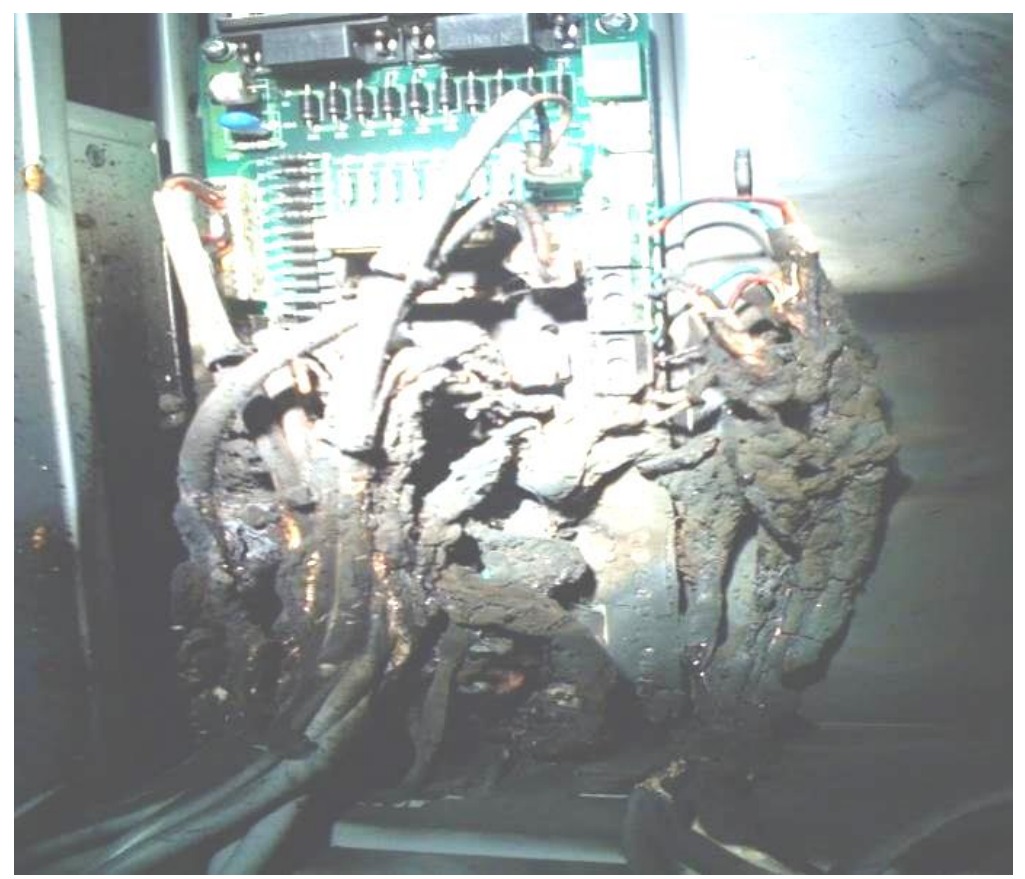

Fig.2 Direct lightning strike of mobile transmission tower on Mukumwanji Hill, Kabwe; damaged equipment 
c) Earthing and bonding systems

The national instrumentation surveys revealed that sensitive electronics equipment at these institutions lacked robust bonding and earthing systems which resulted in equipment malfunctions.

d) Lack or inadequate protection systems

These ongoing surveys continue to show the absence of appreciation of the importance of effective protection and power conditioning of sensitive instrumentation, especially in the absence of the national standards.

\section{e) Poor wiring of both power and ICT data lines}

The survey also revealed poor wiring with regard to power and data lines without due regard to the adverse effects on sensitive equipment caused by crossed lines, loops and mixed power and data cables. The two illustrations below show the widely practiced bad management practice. [6]
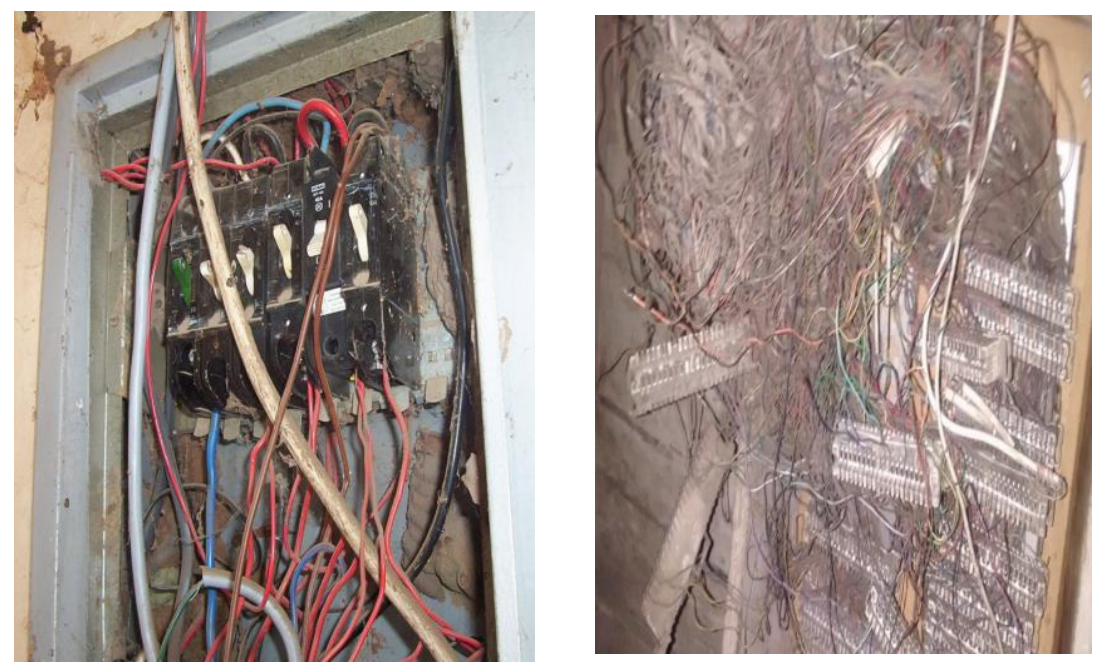

Fig. 3. An example of poor wiring in a DB box and telephone communications lines for a PABX. resulting in poor electrical environment.

4. Remedial strategies [measures] to prevent instrument and system failure revealed in the national instrumentation surveys.

- Power quality improvements

Power line disturbances have remained more or less the same in magnitude and variety for a long time as power demand continue to grow. In earlier days, electromechanical instrumentation was configured using discrete components which were characterized by high dielectric strength. Nowadays semiconductor advances, as a result of high integration, have 
resulted in smaller components with high operating speeds and low dielectric strengths, that require low power supplies, features that make them highly vulnerable to damage when operated in unprotected older electrical environment. [7]

\section{- Lightning protection (LPS)}

Lightning protection through appropriately designed protection systems uniquely suitable for each location. Such systems are designed to intercept direct lightning strikes through air termination spikes, safely channeling lightning current to earth termination through down conductors without affecting contents and persons inside. If such a path is not provided; lightning current will find its way to earth in a disorderly manner destroying equipment, life and civil structures in the process. Lightning protection systems are particularly important for Base Transceiver Station (BTS), which usually have high metallic towers that are vulnerable to lightning strikes.

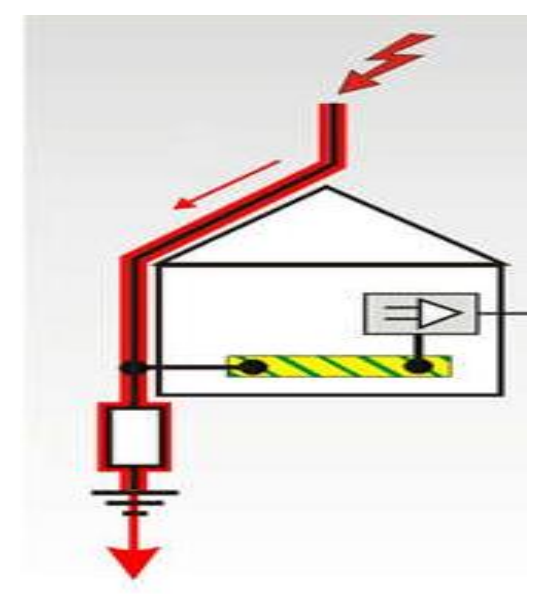

Fig. 4. Lightning protection system (LPS) showing the air termination, down conductors and earth termination. 


\section{- Earthing and bonding}

Earthing systems for instrumentation provide stable potential reference for power and data signals for reliable operation of equipment. When combined with good bonding arrangement, the system can quickly equalize potential difference in the environment, thereby avoiding flow of fault currents through the equipment. [7]
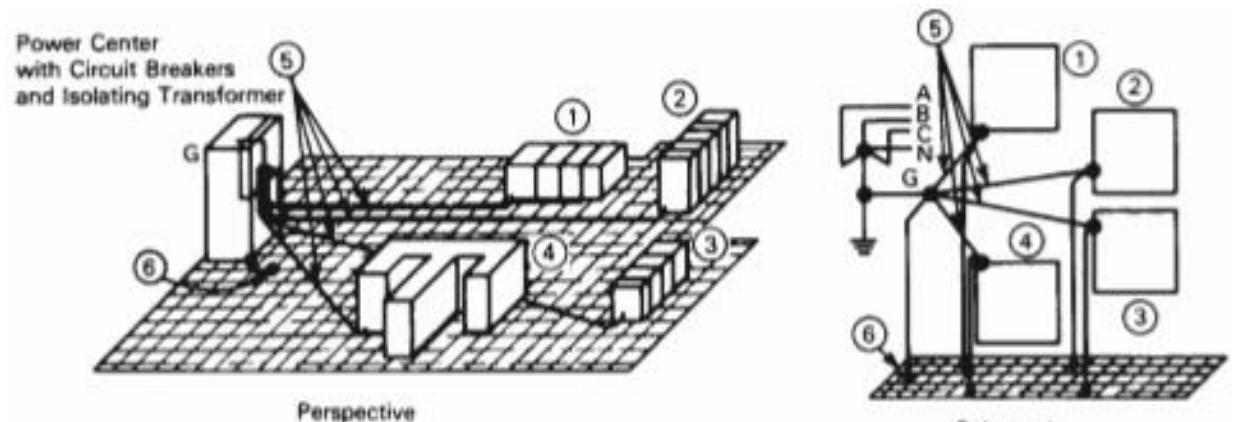

Computer Units Connected to Signal Reference Grid and to A.C Ground

(1) through (4) are typical computer system modules.

(5) is the "Groen Wire" safety equipment ground conductor.

(6) is safety ground for raised floor structure.

Fig. 5. Low impedance bonding scheme showing connection to earthing system, for potential difference equalization.

\section{- Surge protection}

Surge protection devices will intercept transients on data and power lines and shunt them to the earthing and bonding system before they reach the sensitive equipment. Surge protection device installation however require careful installation skills. [8], [9]

\section{- Power conditioning}

Power conditioning converts unconditioned poor utility to suitable conditioned power for equipment. Equipment like isolation transformers, uninterruptible power supplies (UPS), automatic voltage transformers (AVR), constant voltage transformers (CVT), filter etc. are employed. 


\section{- Dedicated power source}

Adequately specified dedicated power supply source that meets the load demand should be utilized for sensitive equipment taking care of load balancing on the phases.

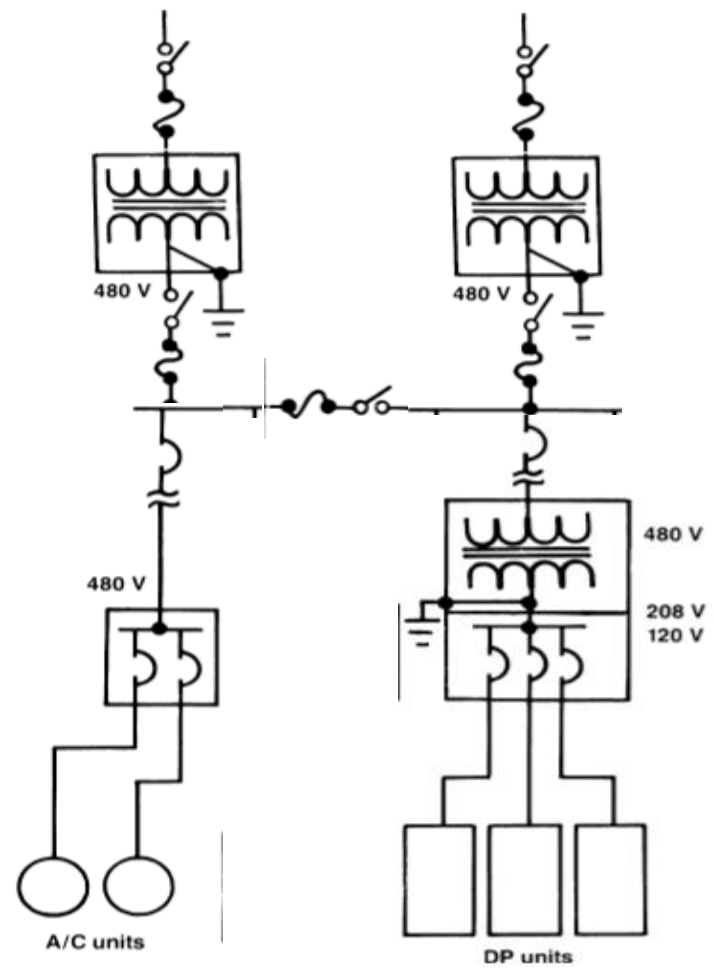

Fig. 6. Separate feeder arrangement using separate transformers to reduce common voltage drop.

\section{- General wiring}

Proper wiring that avoids inductive loops and cable mixing of power and data lines; properly conveyed in well earthed metallic conduits.

The foregoing was proffered to all institutions covered in the survey and are being implemented to varying degrees. 


\section{Conclusion}

This paper has identified and described the electronic equipment and electrical installations rising damages in Zambia as mainly caused by advances in semiconductor technology compounded by the lack of improved electrical environment and poor power quality.

Through efforts made in the surveys carried out, and the continued interaction with these institutions through presentations, many institutions are beginning to be aware of the equipment damage and are beginning to implement the proposed solutions.

In Zambia, efforts are being made by various national regulatory bodies, (ZICTA and ZABS) to implement standards and installation guideline in order to protect equipment from power line disturbances.

\section{References}

1. Schimanski, J., Protecting electrical and electronic system against surge voltages. "Praxisgerechter Uberspannungsschutz" Der Konstrukteur, Issue 1-2/1991

2. How will Nanotechnology change the world? http://www.youtube.com/watch 2015. [Accessed 09/06/17]

3. IAEA Technical Cooperation in Africa, (2016): available on line https://www.iaea.org/technicalcooperation/documents/brochures/2016/T CCAF.pdf [accessed 05/06/17]

4. National Council for Scientific Research: annual report for the year 1994. Internal document

5. Namukolo, K., Due Diligence Audit of Selected ZRA Border ICT Centers, (2007), internal report

6. Namukolo, K, and E.J. Zimba, Due diligence audit report on KCM PLC IT networks, $23-29$ Nov. 2003, internal report

7. Federal Information processing standards publication 94, Guidelines on Electrical Power for ADP Installations. 1993.

Available online: http://www.everyspec.com pdf [accessed 29/04/17]

8. The basics of surge protection, available online:http://www.phoenixcontact.com

9. DEHN+SOHNE- Lightning Protection Guide $3^{\text {rd }}$ updated edition (2014) (available online: https://www.dehn-international.com/en/lightningprotection-guide.pdf.[accessed 28/04/17] 